\title{
Perforated Appendicitis Treated By Open Versus Laparoscopic Surgery- A Comparative Study
}

\author{
Bishow Deep Timilsina' 1 Om Karki², Babita Subedi ${ }^{3}$ \\ 1,2Surgical Department, Manipal Teaching Hospital, Pokhara, Nepal \\ ${ }^{3}$ Pokhara Academy of Health Science, WRH, Pokhara, Nepal
}

\begin{abstract}
BACKGROUND

This work is licensed under a Creative Commons Attribution 4.0 Unported License.

Acute appendicitis is the most common surgical emergency of the abdomen. Perforated appendicitis often has higher morbidity and mortality. Laparoscopic Appendectomy $(\llcorner A)$ is safe and effective procedure for the simple appendicitis compared to Open Appendectomy (OA) but it is not considered as the first line approach in case of perforated appendicitis and its role is still controversial and is under investigation. Hence this study was carried out to compare the outcomes of LA over OA in proven cases of perforated appendicitis.
\end{abstract}

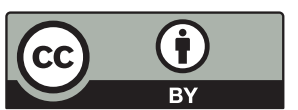

\section{METHODS}

A hospital based comparative study was conducted among 60 patients with the diagnosis of perforated appendicitis who underwent LA and OA, for a duration of 18 months in Manipal Teaching Hospital, Pokhara. Data were collected using semistructured questionnaire and were analyzed by descriptive and inferential statistics with SPSS version 25.0.

\section{RESULTS}

The study showed no significant statistical difference in operative time in LA compared to OA $(66 \pm 18.11$ minutes vs. $66.67 \pm 25.269$ minutes, $p=0.9)$. Moreover it shows less post-operative pain $(p=0.003)$, shorter length of hospital stay ( $5.3 \pm 1.8$ days vs. $7.3 \pm 3.31$ days, $p=0.005)$, faster return of peristalsis $(1.43 \pm 0.504$ days vs $1.80 \pm 0.805$ days, $p=0.037)$ and faster reinstitution of liquid diet $(1.43 \pm 0.504$ days vs $1.80 \pm 0.805$ days, $p=0.037)$, less incidence of wound infection $(5 \mathrm{in} 30=$ $16.66 \%$ vs. 12 in $30=40 \%, p=0.042)$ and faster subjective full recovery $(1.9 \pm 0.759$ weeks vs. $2.9 \pm 0.89$ weeks, $p \quad 0.0001)$ of LA patient compared to OA which is statistically significant.

\section{CONCLUSION}

LA is safe and effective procedure than OA for perforated appendicitis.

\section{KEYWORDS}

Laparoscopic appendectomy, open appendectomy, perforated appendicitis

\section{INTRODUCTION}

Acute appendicitis is the most common cause of acute abdomen. ${ }^{\top}$ Appendectomy is the gold standard treatment for AA. However, conservative treatment is likely to be unfortunate in cases of AA complicated by gangrene or perforation. Delaying the surgical treatment in complicated AA is associated with increase in perforation rates with significant morbidity and mortality. ${ }^{2,3}$

Appendectomy though can be performed by both conventional open and laparoscopic methods, there is a lack of consensus regarding which is the most appropriate method. Keeping in mind this background and the fact that studies comparing LA and OA are fewer in third-world countries like Nepal, this prospective study had documented important variables and parameters to compare therapeutic benefit of $L A$ and $O A$.
Thus, this study was carried out to compare the outcomes of $L A$ and $O A$ in cases of perforated appendicitis, in terms of the duration of operation, post-operative pain, LOHS, complications, recovery and return to normal activities in $L A$ and $O A$.

\section{METHODS}

The cross-sectional comparative study was carried out from August 2019 to January 2021 for 18 months duration in the surgery department of Manipal teaching hospital, Pokhara, Nepal. Ethical approval was taken from the institutional review committee of MCOMS, Pokhara. The total number of 60 patients of the age between 10-60 years with features suggestive of perforated appendicitis within the inclusion

*Corresponding Author

Dr Bishow Deep Timilsina

Surgical Department, Manipal Teaching Hospital, Pokhara, Nepal Email: deepbishow@hotmail.com 
criteria were included in the study following standard sample size formula by randomly assigning them in each group. Patients with an appendicitis without perforation, appendicular mass, abscess, incidental appendectomy, disease of the appendix other than appendicitis were excluded.

After taking written informed consent, semi structured questionnaire is used to collect the patient's subjective and objective data. Their demographic data, operative duration, post-operative pain, return of bowel sound and initiation of oral liquid diet, LOHS and return of subjective full recovery were evaluated. The pain was measured qualitatively by using visual analog scale (VAS).

The data were collected, checked and entered with the help of statistical package for social sciences (SPSS) version 25. Parametric and non-parametric test were applied for data analysis and interpretation was done through tables, piecharts, pictograms, bar graphs and other graphic forms of presentation to summarize the findings and to create a strong visual impression. All reports were reported with $95 \%$ confidence intervals $(95 \% \mathrm{Cl}$ ). P value of 0.05 was considered as a statistically significant.

\section{RESULT}

Among the total 60 patients of perforated appendicitis, most common age group was between 10-20 years comprising $46.66 \%$ with mean age of 26.87 years. Same result was found in both LA and OA group i.e. 19 (63.33\%) patients and 9 patients (30\%) respectively.

Table 1. Comparison of age distribution of patients between $L A$ vs $O A$

\begin{tabular}{|l|l|l|l|l|l|}
\hline $\begin{array}{c}\text { Age } \\
\text { (Years) }\end{array}$ & \multicolumn{2}{|c|}{ LA } & \multicolumn{2}{|c|}{ OA } & \multirow{2}{*}{ P Value } \\
\hline $10-20$ & 19 & $63.33 \%$ & 9 & $30 \%$ & \\
\cline { 1 - 5 } $21-30$ & 6 & $20 \%$ & 8 & $26.66 \%$ & \\
\cline { 1 - 5 } $31-40$ & 2 & $6.66 \%$ & 3 & $10 \%$ & \multirow{2}{*}{0.552} \\
\cline { 1 - 4 } $41-50$ & 2 & $6.66 \%$ & 5 & $16.66 \%$ & \\
\cline { 1 - 4 } $51-60$ & 1 & $3.33 \%$ & 5 & $16.66 \%$ & \\
\hline
\end{tabular}

Moreover the number of male was 39 (65\%) and female was 21 (35\%) with a male to female ratio of 1.8:1. But among LA group, the total number of male was 18 out of 30 (60\%) and the female was $12(40 \%)$ with male to female ratio was 1.5:1 while its was 21 (70\%) and 9 (30\%) for male and female respectively with male to female ratio 2.3:1 in case of OA.

Table 2. Comparison of distribution of patients by their sex between $L A$ vs $O A$

\begin{tabular}{|l|c|c|c|}
\hline \multicolumn{1}{|c|}{ Sex } & Frequency & Percentage & P Value \\
\cline { 1 - 3 } Male & 39 & $65 \%$ & \multirow{2}{*}{0.417} \\
\cline { 1 - 3 } Female & 21 & $35 \%$ & \\
\cline { 1 - 3 } Total & 60 & $100 \%$ & \\
\hline
\end{tabular}

The operative duration between the two operative surgeries observed to be not significant statistically. The minimum to maximum durations was 40 to 110 minutes with mean duration of 66 minutes for LA and 30 to 165 with mean duration of 66.67 for OA.

Table 3. Comparison of operative durations between OA and LA

\begin{tabular}{|l|l|l|l|l|l|}
\hline Surgery & Minimum & Maximum & Mean & $\begin{array}{c}\text { Standard } \\
\text { deviation }\end{array}$ & $\begin{array}{c}P \\
\text { value }\end{array}$ \\
\hline LA & 40 & 110 & 66 & 18.11 & 0.9 \\
\hline OA & 30 & 165 & 66.67 & 25.269 & \\
\hline
\end{tabular}

The post-operative pain scoring done using VAS score on POD 1st, 3rd, 7th, 14th and 28th day revealed the mean VAS score on subsequent days were 4.80, 2.80, 1.00, 1.03 and 0.23 following $\mathrm{OA}$ and $3.30,1.90,0.57,0.20$ and 0.00 following $L A$.

Table 4. Comparison between VAS and types of surgeries (LA vs OA)

\begin{tabular}{|c|c|l|l|l|l|}
\hline VAS & LA & OA & $\begin{array}{c}\mathrm{t} \\
\text {-statistic }\end{array}$ & Pvalue & $\begin{array}{c}\text { Final P } \\
\text { value }\end{array}$ \\
\hline VAS1 & $3.6 \pm 1.113$ & $4.8 \pm 1.69$ & -3.233 & 0.002 & 0.003 \\
\hline VAS3 & $1.9 \pm 1.242$ & $2.8 \pm 1.243$ & -2.805 & 0.006 & \\
\hline VAS7 & $0.57 \pm 0.898$ & $1.0 \pm 1.232$ & -1.545 & 0.127 & \\
\hline VAS14 & $0.20 \pm 0.610$ & $1.03 \pm 1.217$ & -3.339 & 0.001 & \\
\hline VAS28 & $0.03 \pm 0.183$ & $0.23 \pm 0.72$ & -1.475 & 0.1457 & \\
\hline
\end{tabular}

The study shows the range of return of bowel peristalsis was 1-4 days following OA with mean duration of 1.80 days and it was 1-2 days with mean of 1.43 in case of $L A$ indicating that LA has better outcomes in terms of early commencement of diet.

Table 5. Comparison of return of bowel sounds and reinstitution of liquid diet

\begin{tabular}{|l|l|l|l|l|l|}
\hline Procedure & $\begin{array}{c}\text { Minimum } \\
\text { (days) }\end{array}$ & $\begin{array}{c}\text { Maximum } \\
\text { (days) }\end{array}$ & Mean & $\begin{array}{c}\text { Standard } \\
\text { deviation }\end{array}$ & $\begin{array}{c}P \\
\text { value }\end{array}$ \\
\hline LA & 1 & 2 & 1.43 & 0.504 & 0.037 \\
\hline OA & 1 & 4 & 1.80 & 0.805 & \\
\hline
\end{tabular}

This study shows promising results in terms of LOHS in case of $L A$ revealing that the duration of hospital stay ranging from 3 to 10 days with mean LOHS 5.33 days while it was 3 to 15 days with mean LOHS 7.30 days in case of OA.

Table 6. Comparison of LOHS in days between LA vs. OA

\begin{tabular}{|l|l|l|l|l|l|}
\hline Surgery & $\begin{array}{c}\text { Minimum } \\
\text { (days) }\end{array}$ & $\begin{array}{c}\text { Maximum } \\
\text { (days) }\end{array}$ & $\begin{array}{l}\text { Mean } \\
\text { (days) }\end{array}$ & $\begin{array}{l}\text { Standard } \\
\text { deviation }\end{array}$ & Pvalue \\
\hline LA & 3 & 10 & 5.33 & 1.82 & 0.005 \\
\hline OA & 3 & 15 & 7.30 & 3.31 & \\
\hline
\end{tabular}

Comparison of the subjective full recovery i.e. return of the normal daily activities including domestic and social life 
revealed better results in case of LA with mean duration of 1.90 weeks (range 1 - 3 weeks) compared to longer duration with mean 2.97 weeks ( range 2 - 5 weeks) in case of OA.

Table 7: Comparison of return of normal activities between LA vs $O A$

\begin{tabular}{|l|l|l|l|l|l|}
\hline Surgery & $\begin{array}{c}\text { Minimum } \\
\text { (weeks) }\end{array}$ & $\begin{array}{c}\text { Maximum } \\
\text { (weeks) }\end{array}$ & $\begin{array}{c}\text { Mean } \\
\text { (weeks) }\end{array}$ & $\begin{array}{l}\text { Standard } \\
\text { deviation }\end{array}$ & P value \\
\hline LA & 1 & 3 & 1.90 & 0.759 & $<0.0001$ \\
\hline OA & 2 & 5 & 2.97 & 0.89 & \\
\hline
\end{tabular}

This study showed significantly lower rate of wound infection 5 in 30 patients (16.66\%) following LA compared to 12 in 30 cases (40\%).

Table 8: Comparison of wound infection between LA vs OA.

\begin{tabular}{|l|l|l|l|l|}
\hline \multicolumn{1}{|c|}{ Surgery } & $\begin{array}{c}\text { Total } \\
\text { patients }\end{array}$ & $\begin{array}{c}\text { Wound } \\
\text { infection }\end{array}$ & Percentage & P value \\
\hline LA & 30 & 5 & $16.66 \%$ & \multirow{2}{*}{0.042} \\
\hline OA & 30 & 12 & $40 \%$ & \\
\hline
\end{tabular}

\section{DISCUSSION}

Acute appendicitis has been one of the most common surgical emergency worldwide. ${ }^{4}$ Perforated appendicitis occurs in $20 \%$ to $30 \%$ of acute appendicitis patients and is associated with much higher risks of postoperative infectious complications such as wound infection and intra-abdominal abscess. However, only a few studies, with limited numbers of patients, have addressed the issue of whether $L A$ is feasible for perforated appendicitis patients, and the benefits of $L A$ in perforated appendicitis remain uncertain. ${ }^{5}$ It is said that LA is possible, secure, and effective for patients with perforated appendicitis. It is associated with a considerably shorter LOHS, lower incidence of wound infection, and reduced postoperative pain and faster recovery compared with $\mathrm{OA} .{ }^{6,7}$ Though many controversies exist regarding the most favorable management modality of patients with appendicular perforation. ${ }^{6}$

In this study, the total number of appendectomy was 318 during the study period among which 60 patients (18.86\%) were diagnosed as having perforated appendicitis. LA was performed in 30 patients and $\mathrm{OA}$ in rest 30 . There was no statistical significance between age and sex distribution with the perforated appendicitis treated by both LA and OA. There was a higher male predominance both in LA and OA, $18(60 \%)$ vs 21 (70\%) with female patients 12 (40\%) vs 9 (30\%) with $P=0.417$. Similar findings was seen in the study carried out by Lin HF et. Al. ${ }^{5}$

Moreover this study revealed no significant statistical difference i.e. similar operative duration for both $L A$ and $O A$ groups (mean \pm SD $=66.0 \pm 18.11$ minutes vs. $66.67 \pm 25.26$ minutes, $p=0.9$ ), which is also supported by a literature. ${ }^{19}$ But most studies for adult showed LA has similar results or longer operative time than OA (Mean \pm SD $=96.1 \pm 43.1$ vs. $67.8 \pm 32.2$ minutes, $p 0.01)^{5}$, while few reported the shorter operative time than OA.61 The post-operative pain measured by VAS scale on 1st, 3rd, 7th, 14th and 28th day was significantly low in LA compared to OA $(3.30 \pm 1.133$, $1.90 \pm 1.242, \quad 0.57 \pm 0.898, \quad 0.20 \pm 0.61, \quad 0.00 \pm 0.183$ vs. $4.80 \pm 1.690,2.80 \pm 1.243,1 \pm 1.232,1.03 \pm 1.217,0.23 \pm 0.728$, $p=0.003)$.

Likewise Lin et. al has mentioned some studies showed the value of $L A$ in reducing the postoperative analgesics use, and concluded that LA cause less pain than OA for adult patients with perforated appendicitis. ${ }^{7}$

My study revealed early return of peristalsis and restart of oral feeding in case of LA compared to OA (1.43 \pm 0.504 days vs. $1.80 \pm 0.805$ days, $p=0.037)$. Likewise, Lin et al showed return of oral intake was faster in the LA group $(3.2 \pm 2.4$ vs. $5.0 \pm 7.0$ days, p 0.01). ${ }^{5}$ Some studies have shown that there was no significant difference in the time of restart of oral intake between LA and OA for children with perforated appendicitis. Fukami et. al and the other series also demonstrated the same trend. However, lack in a precise definition of restart of oral intake (liquid or solid food) in these studies precluded a further analysis. ${ }^{?}$

Most of the studies concluded that LA was associated with a shorter hospital LOS compared to OA for perforated appendicitis. ${ }^{5-8,12,14}$ In a similar way, this study also shows shorter LOS by 2 days in case of LA compared to OA (5.33 \pm 1.826 days vs. $7.30 \pm 3.313$ days, $p=0.005$ ). Different studies have found that the infection rate is low in LA patient in comparison to OA case. ${ }^{8-14}$ Similarly this study also revealed that the less infection rates in $L A$ ( 5 in 30 patients $=16 \%$ ) compared to OA (12 in 30 patients $=40 \%$ ) with $p$ $=0.042$. In practice, the appendix was placed in a retrieval plastic bag or retrieved out through $10 \mathrm{~mm}$ camera port under direct $5 \mathrm{~mm}$ camera vision and the accumulated fluid was aspirated before closing the wound in laparoscopic appendectomy procedure. These maneuvers prevent the abdominal wall from being in contact with the infected source, and thus reduce the rate of wound infection.

Likewise this study showed that the subjective full recovery i.e. return to normal domestic or social life is also faster in LA group compared to OA (1 - 3 weeks with mean 1.90 weeks vs $2-5$ weeks with mean 2.97 weeks with $P=$ 0.0001).Readmission was done due to features of subacute intestinal obstruction (SAIO) with post-operative intraabdominal abscess (IAA) in 2 cases of OA group (6.66 $\%)$. Similarly some studies have shown the rates of postoperative IAA is similar or even lower in LA compared to OA. Masoomi et al also reported a superior outcome of reducing the rate of IAA in LA than OA $(1.65 \%$ vs $3.57 \%, P<0.01)$ on a large administrative basis. However, the incidences of IAA following LA for perforated appendicitis were still 
high in some recent reports. ${ }^{7}$ This study showed the conversion from LA to OA in 8 out of 30 patients (26.66 \%). The conversion was usually due to perforated appendicitis associated with lump formation, IAA and dense adhesion. 5,7

\section{CONCLUSION}

LA has been more frequently used for perforated appendicitis in adults and children by surgeons experienced in laparoscopy. Many studies have concluded that LA is superior to OA in terms of a faster recovery and less morbidities, shorter LOHS, lower wound infection rate compared to OA for patients with perforated appendicitis. LA may be beneficial for some subsets of population, such as female, elderly and obese patients. It deserves more randomized and population-based studies to definite the actual roles of LA in the management of perforated appendicitis.

Though LA has no significant difference in operative time compared to OA in this study, it has significantly less postoperative pain, faster recovery in terms of return of bowel sounds and reinstitution of oral feeding, shorter LOHS, Iow complication rates like infection, SAIO, IAA and faster subjective full recovery. Hence, this prospective study concludes that LA can be a safe and effective procedure in case of perforated appendicitis and it is probably superior compared to $\mathrm{OA}$ in the hands of expertise laparoscopic surgeons.

\section{CONFLICT OF INTEREST: NONE}

\section{FUNDING: NA}

\section{REFERENCES}

1. Mulsow J. The Vermiform Appendix. In: Williams NS, O'Connell PR, McCaskie AW, editors. Bailey \& Love's Short practice of surgery. 2. 27 ed. 6000 Broken Sound Parkway NW Suite 300: CRC press; 2018. 1299-317.

2. Limpawattanasiri $C$. Alvarado score for the acute appendicitis in a provincial hospital. J Med Assoc Thai. 2011;94(4):441.

3. Temple CL, Huchcroft SA, Temple WJ. The natural history of appendicitis in adults. A prospective study. Ann Surg. 1995;221(3):278.

4. Beecher SM, Hogan J, O'Leary DP, McLaughlin R. An appraisal of inflammatory markers in distinguishing acute uncomplicated and complicated appendicitis. Dig Surg. 2016;33(3):177-81.

5. Lin $\mathrm{H}-\mathrm{F}$, Wu J-M, Tseng L-M, Chen $\mathrm{K}-\mathrm{H}$, Huang $\mathrm{S}-\mathrm{H}$, Lai I-R. Laparoscopic versus open appendectomy for perforated appendicitis. J Gastrointest Surg. 2006;10(6):906-10.

6. Mohajerzadeh L, Rouzrokh $M$, Ahmad KT, Mirshemirani A, Atqiaee K, Dara N. Laparoscopic appendectomy in complicated appendicitis of children. Ann Colorectal Res. 2014;2:16599.

7. Lin H-F, Lai H-S, Lai I-R. Laparoscopic treatment of perforated appendicitis. World J Gastroenterol: WJG. 2014;20(39):14338.
8. Park JY, Choe YM, Yun MY, et al. Laparoscopic versus open appendectomy for perforated appendicitis in children. J Korean Surg Soc. 2008;75(2):116-9.

9. Vahdad MR, Troebs R-B, Nissen M, Burkhardt LB, Hardwig S, Cernaianu G. Laparoscopic appendectomy for perforated appendicitis in children has complication rates comparable with those of open appendectomy. J Pediatr Surg. 2013;48(3):55561.

10. Kirshtein B, Bayme M, Domchik S, Mizrahi S, Lantsberg L. Complicated appendicitis: laparoscopic or conventional surgery? World J Surg. 2007;31(4):744-9.

11. Garg CP, Vaidya BB, Chengalath MM. Efficacy of laparoscopy in complicated appendicitis. Int J Surg. 2009;7(3):250-2.

12. Gundavda M, Bhandarwar A. Comparative study of laparoscopic versus open appendicectomy. Indian J Med Sci. 2012;66(5/6):99.

13. Goudar B, Telkar S, Lamani Y, Shirbur S, Shailesh M. Laparoscopic versus open appendectomy: a comparison of primary outcome studies from southern India. J Clin Diagn Res. 2011;5:1606-9.

14. Yau KK, Siu WT, Tang CN, Yang GPC, Li MKW. Laparoscopic versus open appendectomy for complicated appendicitis. J Am Coll Surg. 2007;205(1):60-5. 